\title{
Conjunctival herpetic ulcer in an immunosuppressed patient with birdshot chorioretinopathy
}

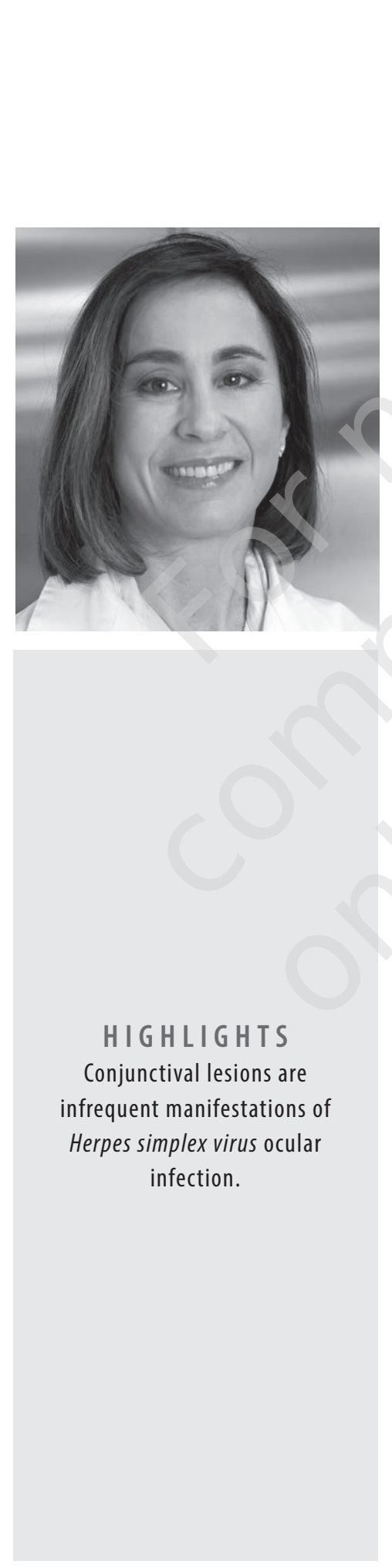

\author{
Ana Fernández-Hortelano ${ }^{1}$, Elena Guzmán-Almagro ${ }^{1}$, \\ María Castro Rebollo ${ }^{1}$, Carlos Izquierdo Rodríquez', \\ Julio González Martín-Moro ${ }^{1,2}$ \\ 'Ophthalmology Department, University Hospital of Henares
} Head: Rosario Cobo-Soriano, MD, PhD

${ }^{2}$ Department of Medicine, University Francisco de Vitoria Head: Prof. Fernando Caballero Martínez, MD, PhD

\section{ABSTRACT}

Introduction: Herpes simplex virus is a human herpesvirus responsible for systemic infections. Ocular involvement spans all ocular tissues. Corneal lesions, such as dendritic or geographic ulcers, are frequently found in keratitis while conjunctival lesions have been described as infrequent.

Clinical case: A 62-year-old man diagnosed with birdshot chorioretinopathy presented a stye in his eyelid that was treated with oxytetracycline-hydrocortisone ointment. One week later he returned presenting several small dendritic corneal ulcers in both eyes and a conjunctival ulcer in one of them. All lesions healed completely after treatment with topical acyclovir ophthalmic ointment at $3 \%$.

Conclusions: We should pay attention to the conjunctiva and not merely focus on the cornea when examining patients with herpetic eye disease, especially if being treated with immunosupressors.

Key words: conjunctival ulcers, herpetic keratitis, Herpes simplex virus, birdshot chorioretinopathy, immunosuppression, topical steroids 


\section{INTRODUCTION}

Herpes simplex virus (HSV) ocular infection constitutes one of the main causes of corneal blindness worldwide and significantly impairs quality of life among those affected. Visually significant complications associated with HSV keratitis arise from the complex interplay between viral activity and the host immune response [1]. HSV is responsible for a variety of ocular diseases in the anterior and posterior segment, but most commonly it involves the anterior segment. Corneal lesions, such as dendritic or geographic ulcers, are frequently found in HSV keratitis while conjunctival lesions have been described as infrequent [2].

\section{CLINICAL CASE}

A 62-year-old man diagnosed with birdshot chorioretinopathy (HLA-A29 positive) presented with one-week history of foreign body sensation and redness in his right eye (RE). His current treatment for birdshot chorioretinopathy was prednisone $5 \mathrm{mg}$ every 24 hours, cyclosporine $150 \mathrm{mg}$ every 12 hours and mycophenolate $1 \mathrm{~g}$ every 12 hours. The treatment was initiated one month before, after being diagnosed of birdshot chorioretinopathy. The patient did not have history of herpetic disease. A slit lamp examination showed the presence of a stye in his lower right eyelid and treatment with oxytetracycline-hydrocortisone ointment was started. The ocular surface was not affected at that moment. One week later he returned because the symptoms had not improved. Several small dendritic corneal ulcers were present in both eyes. The right eye also showed a conjunctival ulcer in the temporal conjunctiva (fig. 1). Rest of the anterior segment was unremarkable. Fundus examination in both the eyes was within normal limits.

\section{FIGURE $(1$}

Examination at diagnosis under a cobalt blue filter disclosed several corneal lesions and two conjunctival ulcers. A. Temporal herpetic conjunctival ulcer. B. Herpetic corneal and conjunctival affection. C. Nasal herpetic conjunctival ulcer.

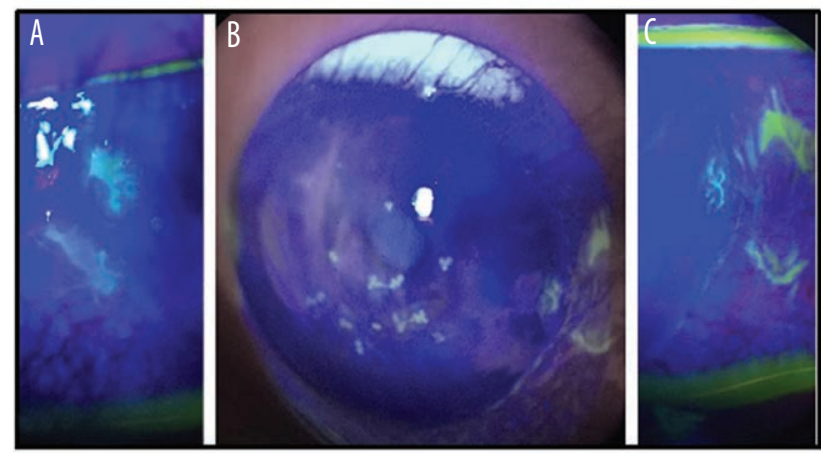

Treatment with oxytetracycline-hydrocortisone ointment was stopped and topical acyclovir ophthalmic ointment at $3 \%$ five times/day was started. Both the corneal and conjunctival lesions healed almost completely 2 days later, there was superficial punctuate keratitis in the inferior half of the cornea (fig. 2). Treatment was gradually discontinued. 2 weeks later all the lesions had cured.
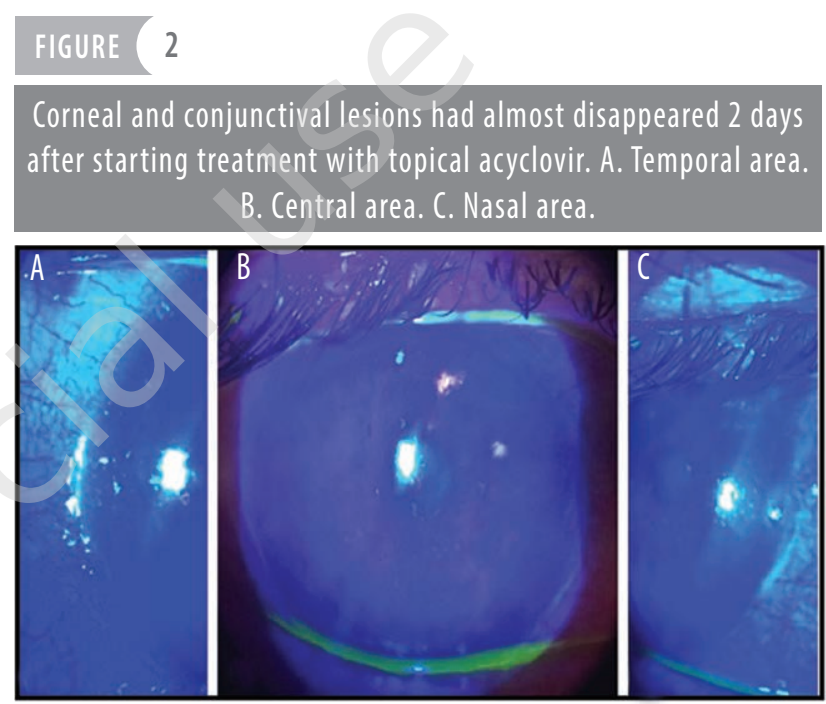

\section{DISCUSSION}

We report a patient with herpetic disease triggered by topical corticosteroids in the context of systemic immunosuppression for birdshot chorioretinopathy. The reactivation of latent HSV-1 has been associated with several stressors, including drugs and fever. Local immunosuppression such as that induced by topical corticosteroids can reactivate and exacerbate HSV keratitis [3, 4]. Herpetic keratitis has been reported after using eye drops, intravitreal and subconjunctival injection of steroids [5]. Our patient did not show herpetic keratitis while receiving systemic steroids but topical steroids administration or maybe the conjunction of both, oral and topical steroids, may have reactivated the virus.

Only a few cases of conjunctival herpetic ulcers have been previously reported [6-9]. Nevertheless, they could be more prevalent than previously thought as professionals focus their attention on corneal lesions rather than on conjunctival lesions.

In the presence of the typical dendritic or geographical shape, diagnosis is straightforward. Nevertheless, herpetic conjunctival ulcers can adopt other patterns and mimic other diseases such as peripheral ulcerative keratitis (PUK) [7]. The presence of multiple conjunctival ulcers has been described previously [10]. Diagnostic certainty is based on 
viral isolation, PCR and serologic tests [10]. In primarily immune-mediated forms, diagnosing HSV is primarily a clinical diagnosis based on appearance and response to empiric treatment. In the reported case we did not isolate the virus but the dendritic pattern of the conjunctival and corneal ulcers, and the fast and complete response to antiviral treatment, strongly suggests a herpetic etiology. The effectiveness of topical 3\% acyclovir ophthalmic ointment has previously been reported in the treatment of conjunctival herpetic ulcers [7-10]. Epithelial keratitis usually self-resolves in 2 weeks, but early initiation of topical or systemic antiviral medication reduces disease severity and course. Systemic agents are preferred over topical medications by many cornea specialists because of the high bioavailability, avoidance of surface toxicity and ease of administration [1]. The patient did not have a history of herpetic disease but primary infection with HSV-1 is silent in the majority of cases. In HSV infections, besides loss of corneal sensitivity and presence of typical skin lesions, dendritic or geographic patterns of conjunctival ulcers may be an important sign that contributes to the ability to distinguish HSV from adenoviral keratoconjunctivitis. We cannot be certain whether the patient had a primary or a recurrent HSV infection. Though less common, bilateral conjunctival geographic ulcers in primary HSV infection have already been reported [10].

\section{CONCLUSION}

We conclude that when examining patients with herpetic eye disease, especially when being treated with immunosupressors, we should pay attention to the conjunctiva and not merely focus on the cornea.

Figures: from the author's own materials.

\section{CORRESPONDENCE}

Ana Fernández-Hortelano, MD, PhD

Av. de Marie Curie, 0, 28822 Coslada, Madrid, Spain

phone: +34636496608

e-mail: anaferh@gmail.com

\section{ORCID}

Ana Fernández-Hortelano - ID - http://orcid.org/0000-0002-3734-3707

Elena Guzmán-Almagro - ID - http://orcid.org/0000-0003-4448-9293

María Castro Rebollo - ID - http://orcid.org/0000-0001-6007-9265

Carlos Izquierdo Rodríquez - ID - http://orcid.org/0000-0002-3335-007X

Julio González Martín-Moro - ID - http://orcid.org/0000-0002-8056-2630

\section{References}

1. Valerio GS, Lin ChC. Ocular manifestations of herpes simplex virus. Curr Opin Ophthalmol. 2019; 30: 525-31.

2. Laibson PR. Current therapy of herpes simplex virus infection of the cornea. Int Ophthalmol Clin. 1973; 13: 39-52.

3. Holland EJ, Fingeret M, Mah FS. Use of topical steroids in conjunctivitis: a review of the evidence. Cornea. 2019; 38: $1062-7$.

4. American Academy of Ophthalmology Cornea/External disease preferred practice pattern. Panel. Preferred practice pattern Guidelines: Conjunctivitis 2019. https://www.aao.org/preferredpractice-pattern/conjunctivitis-ppp-2018 (access: 12.12.2018).

5. Shtein RM, Stahl RM, Saxe SJ et al. Herpes simplex keratitis after intravitreal triamcinolone acetonide. Cornea. 2007; 26: 641-2.

6. Kline LB, Jackson B. Herpes Zoster Conjunctival Ulceration. Canad J Ophthalmol. 1977; 12: 66-7.

7. Zaher SS, Sandinha T, Roberts F et al. Herpes simplex keratitis misdiagnosed as rheumatoid arthritis-related peripheral ulcerative keratitis. Cornea. 2005; 24: 1015-7.

8. Sridhar U, Bansal Y, Choudhury S et al. Conjunctival dendrite in a case of primary herpes simplex infection. Br J Ophthalmol. 2004; 88: 590-1.

9. Swaroop R. Conjunctival geographic ulcer and blepharitis in primary ocular herpes: a case report. Cases J. 2009; 2: 8141.

10. Hung JH, Chu CY, Lee CN et al. Conjunctival geographic ulcer: an overlooked sign of herpes simplex virus infection. J Clin Virol. 2015; 64: 40-4. 


\section{Authors' contributions:}

Elena Guzman-Almagro: contribution in the editing of the paper and bibliography search; Maria Castro-Rebollo: contribution in the images; Carlos Izquierdo-Rodríguez: contribution in assisting the patient and bibliography search; Julio González Martin-Moro: contribution in the editing of the paper and bibliography search.

\section{Conflict of interest:}

None.

\section{Financial support:}

None.

\section{Ethics:}

The content presented in the article complies with the principles of the Helsinki Declaration, EU directives and harmonized requirements for biomedical journals. 